\title{
Dual Band Notch, Compact, Low profile, Hybrid Ultra Wideband RDRA
}

\author{
Taruna Sharma, Parikshit Vasisht, Munish Vashishath, R. S. Yaduvanshi
}

\begin{abstract}
This paper presents a novel, compact Ultra Wide Band, Asymmetric Ring Rectangular Dielectric Resonator Antenna (ARRDRA), which is a unique combination of Thin Dielectric Resonator (DR), Fork shape patch and defective ground structure. The base of the proposed antenna is its Hybrid structure, which generates fundamental TM, TE and higher order modes that yields an impedance bandwidth of $119 \%$. Proposed antenna provides a frequency range from 4.2 to $16.6 \mathrm{GHz}$ with a stable radiation pattern and low cross polarization levels. Peak gain of $5.5 \mathrm{~dB}$ and average efficiency of $90 \%$ is obtained by the design. Antenna is elongated on a FR4 substrate of dimension 20 $x 24 x 2.168 \mathrm{~mm} 3$ and is particularly suitable for C band INSAT, Radio Altimeter, WLAN, Wi-Fi for high frequencies. Ease in fabrication due to simplicity, compactness, stable radiation pattern throughout the entire bandwidth are the key features of the presented design. Inclusion of Defective ground structure and asymmetric ring not only increases the bandwidth but also stabilize the gain and efficiency due to less surface current. Presented design launch an Ultra Wide Band antenna with sufficient band rejection at 4.48-5.34 and 5.64-8.33 GHz with stable radiation pattern and high gain.
\end{abstract}

Keywords-Asymmetric Ring Rectangular Dielectric Resonator Antenna (ARRDRA), Microstrip Patch Antenna (MPA), Ultra Wideband, Multimode Resonance, Microstrip feed.

\section{INTRODUCTION}

In this era of technological advancement, when $6 \mathrm{G}$ is ready to knock the door of wireless communication, every antenna designer is trying to render ultra wide bandwidth with high data transfer rate that too with ease in size allocation. In last 25 years, Dielectric Resonator Antenna (DRA) is evolving as a prolific, ultra wideband , low profile and efficient radiator. DRA is a lossless radiator, educing various merits like wideband nature, compactness in size, light weight offering high temperature stability, low cost and ease of fabrication [1]. DRA displays high radiating efficiencies due to absence of any kind of conductors in the radiator. Moreover, these dielectric radiators are highly compatible with every kind of transmission lines such as coaxial probe, micro-strip line, micro-strip slot, coupled or

Revised Manuscript Received on September 25, 2020.

* Correspondence Author

Taruna Sharma*, PhD Scholar in Department of Electronics \& Communication at J. C. Bose University of Science and Technology. YMCA, Faridabad, India.

Dr. Parikshit Vasisht, Assistant Professor in Pesjay Stya University, Gurgaon (Haryana), India.

Dr. Murnish Yashnath Department of Electronics and Communication, Bose University of Science and Technology, YMCA Fandabad, India

R.S. Yaduvanshi, Institute of Advanced Communication Technologies and Research (AIACTR). Govt Dethi India

(C) The Authors. Published by Blue Eyes Intelligence Engineering and Sciences Publication (BEIESP). This is an open access article under the CC BY-NC-ND license (http://creativecommons.org/licenses/by-nc-nd/4.0/) aperture coupled, coplanar waveguide and dielectric image guide method [2].Array formation is the best way to increase bandwidth and maintain high gain at the same time but if we consider only single element bandwidth enhancement methods includes lowering Q-factor, modifying feed mechanisms and multi segmentation of the DRA's .Bandwidth of the DRA can be enhanced with the reformed geometries. L-shape [3] and Asymmetrical T-shape[4] DRA's have been proposed to enhance the bandwidth from usual $10 \%$ to $38 \%$ and $75.1 \%$ respectively. Combination of shape modification along with restructured feed is proposed in[5] where L shape probe is applied in the groove space created between DRA and the ground plane hence yields an impedance bandwidth of 32\%. Conformal inverted trapezoidal patch and microstrip integration with renewed L Shape of DRA is proposed in [6] that not only gives $70 \%$ bandwidth with stable bidirectional radiation pattern but also yields high gain ranging from (5-8.5 dBi). Compact and low profile antennas in combination with Ultra wide band characteristics are not lesser than any boon in today's swift communication era. A- shape compact antenna with stair shape feed [7] with ultra wide bandwidth and high efficiency and a CPW fed antenna[8] which is compacted by $50 \%$ is proposed with steady gain. Modified feed mechanisms like U-shaped stair shape microstrip feed[9] is applied to a multi segment DRA, which is another way of achieving UWB. Annular shape [10] microstrip feed in conjunction with ring DRA is presented. Other Techniques of obtaining UWB Antennas include using pairs of compact DRA placed adjacently and asymmetrically, fed by single rectangular Aperture [11] also same arrangement fed by two rectangular adjacent slots[12].Multiple slab structures or multisegment antenna with different permittivity are placed side by side provides wide band width also inclusion of Defective Ground Structure provide high gain with stable radiation pattern. Adjustment in positions of two low profile DRA's, microstrip feed sandwich between them provides UWB of $88.2 \%$ [13] Latest effective technique of Sandwiching micro strip feed between two low profile DRA's is also proposed in[14] to achieve UWB DRA Many techniques have been devised to suppress unwanted signal interference in WLAN and Wi-Fi and ITU bands of UWB system provided by FCC in the frequency range 3-10 GHz. Insertion of stubs and parasitic strips[15] and using modified DRA geometries [16] with altered feed mechanism is serving the purpose. In this paper, a detail investigation on Fork shape feed, low profile DRA is carried out. A compact, miniaturized, antenna is proposed which not only solve the space constraint of the UWB systems but also can be fitted into any hand held device for 4.2-16.6 $\mathrm{GHz}$ range.

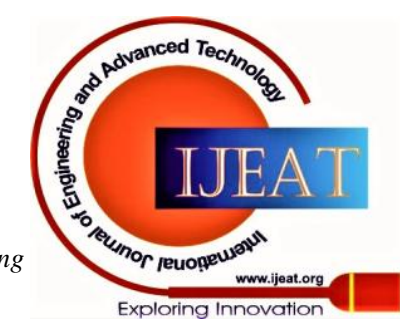


Dual Band Notch, Compact, Low profile, Hybrid Ultra Wideband RDRA

DGS technique of bandwidth enhancement is applied in the design. Partial ground structure with a slot in center and use of conducting strip not only increases the bandwidth but also increases gain of the antenna. Incorporation of the asymmetric ring in DRA reduces the quality factor of DRA, which in turn improve cross and co polarization of the design. In this paper, section II describes geometry and designing concepts of the antenna. Section III demonstrates results obtained and discusses various aspects of the resulting graphs. Section IV delineates the conclusion part of the article.

\section{ANTENNA GEOMETRY AND DESIGN}

Fig. 1. Shows the geometric configuration of a ARDRA ( Asymmetric Rectangular Dielectric Resonator Antenna). A compact RDRA is designed having a red ground of $10 \times 24$ $\mathrm{mm}^{2}$ and a substrate material of FR4 epoxy, permittivity of 4.4 with dimensions of $20 \times 24 \times 1.6 \mathrm{~mm}^{3}$. Rectangular DRA is made of TMM13i with permittivity of 12.8. Feeding mechanism used here is microstrip plus conjunction with fork shape feed coupling method.

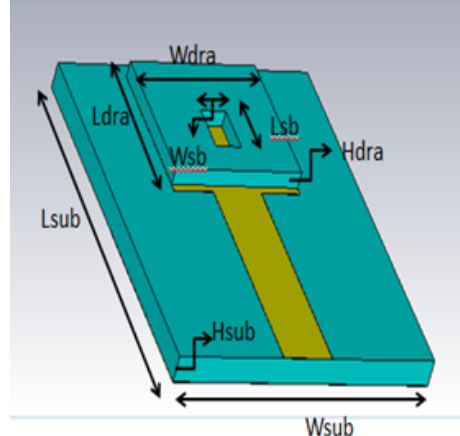

Fig. 1(a)

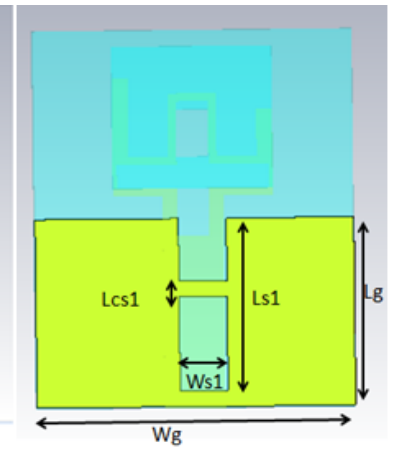

Fig.1(b)
Geometrical configuaration of proposed design

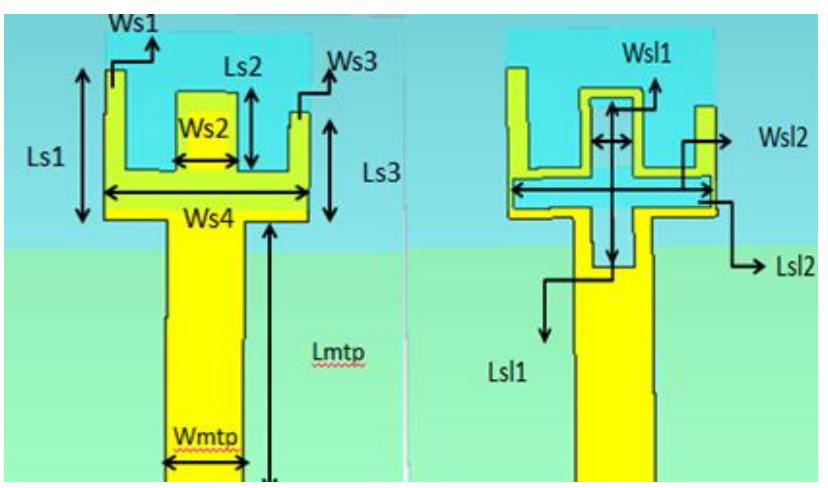

Fig. 1(c)

Fig. 1(d)

Fig. 1. Geometrical configuration of proposed design

\begin{tabular}{|c|c|c|c|}
\hline S.no. & $\begin{array}{l}\text { Antenna } \\
\text { Part }\end{array}$ & Dimensions(mm) & $\begin{array}{c}\text { Material } \\
\text { used }\end{array}$ \\
\hline 1. & Substrate & $\begin{array}{c}\text { WsubxLsubXHsu } \\
\text { b } \\
=20 \times 24 \times 1.6\end{array}$ & $\begin{array}{l}\text { FR4 }(\varepsilon \mathrm{r} \\
=4.4)\end{array}$ \\
\hline \multirow[t]{4}{*}{2.} & \multirow{4}{*}{$\begin{array}{l}\text { Fork shape } \\
\text { feed }\end{array}$} & Ws1xLs1 =1x7.5 & \multirow{7}{*}{ Copper } \\
\hline & & Ws2xLs2 =1x5.5 & \\
\hline & & Ws3xLs3 =3x4 & \\
\hline & & Ws4 =1.5 & \\
\hline \multirow[t]{3}{*}{3.} & \multirow[t]{3}{*}{ Ground } & WgxLg =20x10 & \\
\hline & & Ws1xLs1 =3.5x11 & \\
\hline & & Lcs1=1 & \\
\hline 4. & DRA & $\begin{array}{l}\text { WdraxLdraXHdra } \\
=10 \times 9 \times 1\end{array}$ & $\begin{array}{c}\text { TMM13 } \\
\mathrm{i}(\varepsilon \mathrm{r}=12.8)\end{array}$ \\
\hline
\end{tabular}

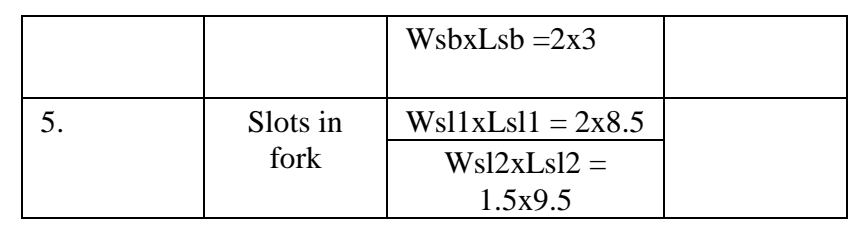

III. RESULTS AND DISCUSSION

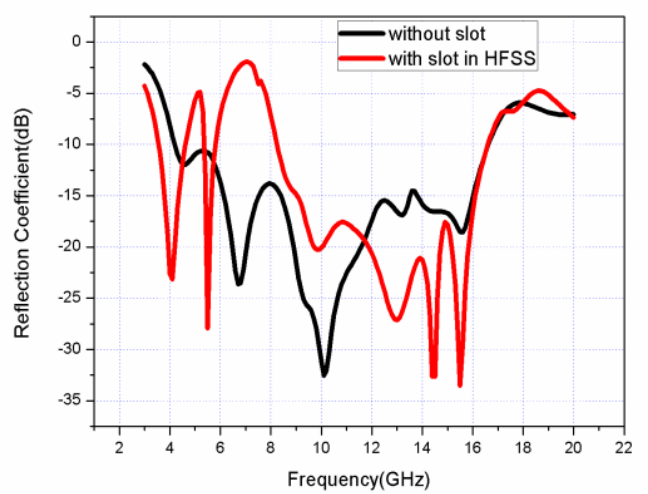

Fig.(2) S11 with and without slot in HFSS.

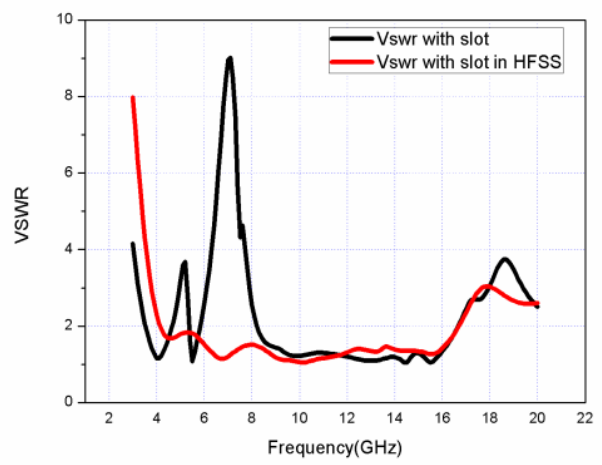

Fig.(3) VSWR with and without slot in HFSS.

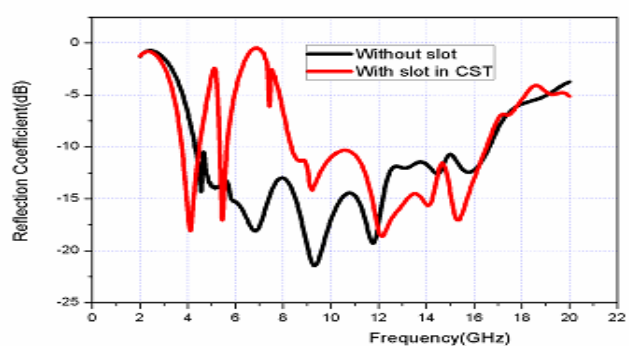

Fig.(4) S11 with and without slot in CST.

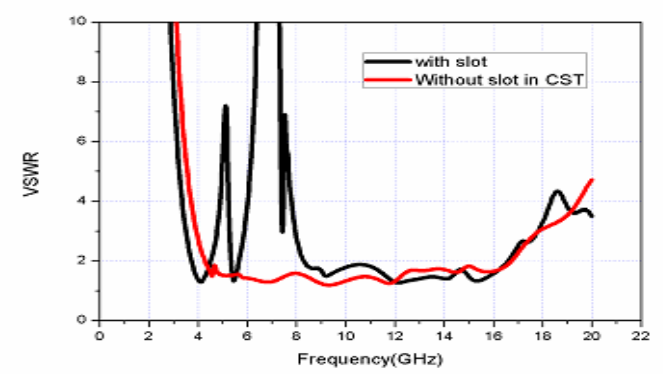

Fig.(5) S11 with and without slot in CST.

Published By:

Blue Eyes Intelligence Engineering and Sciences Publication

(C) Copyright: All rights reserved.

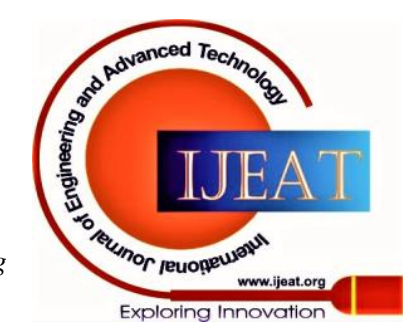




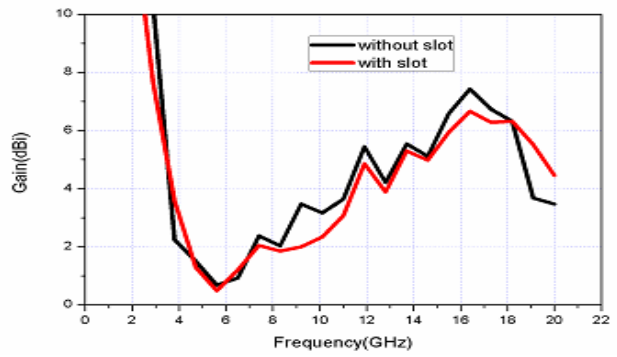

Fig.(6) Gain drop in DRA with and without slot

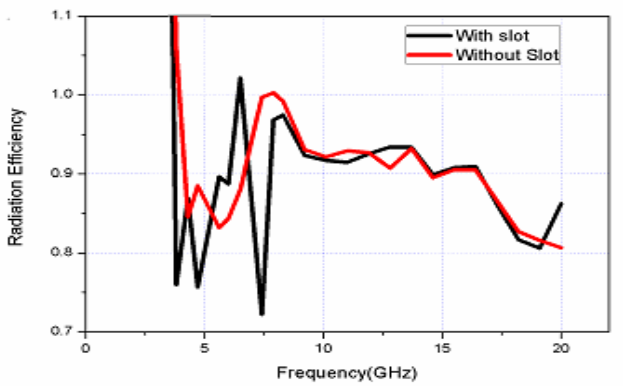

Fig (7) depicts drop in efficiency at band rejection frequencies.

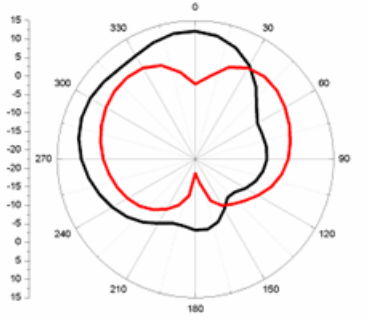

E-plane at $4.5 \mathrm{GHz}$ at phi $=0$

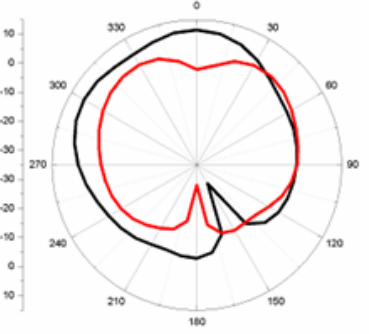

E-plane at $5.5 \mathrm{GHz}$ at phi $=0$

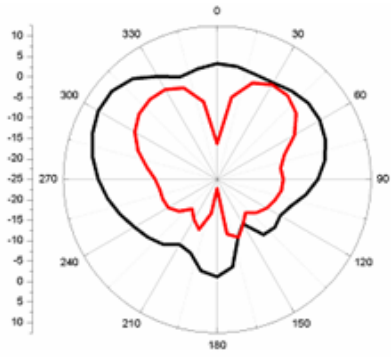

E-plane at $7.5 \mathrm{GHz}$ at phi $=90$

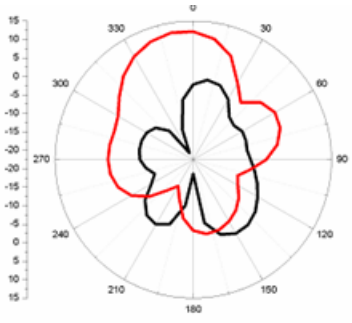

H-plane at $4.5 \mathrm{GHz}$ at phi $=90$

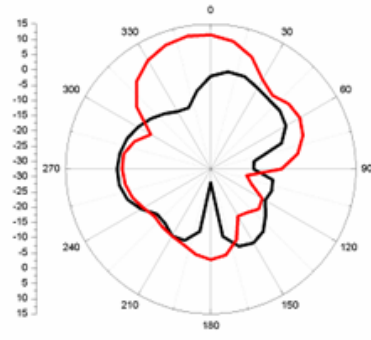

H-plane at $5.5 \mathrm{GHz}$ at phi $=90$

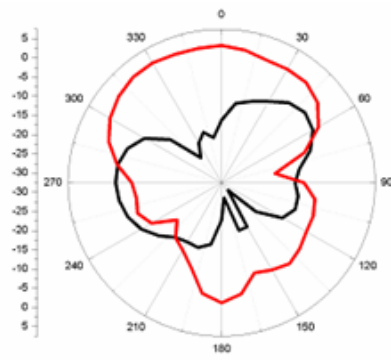

H-plane at $7.5 \mathrm{GHz}$ at $\mathrm{phi}=90$
Fig (8) Radiation Pattern at various frequencies.

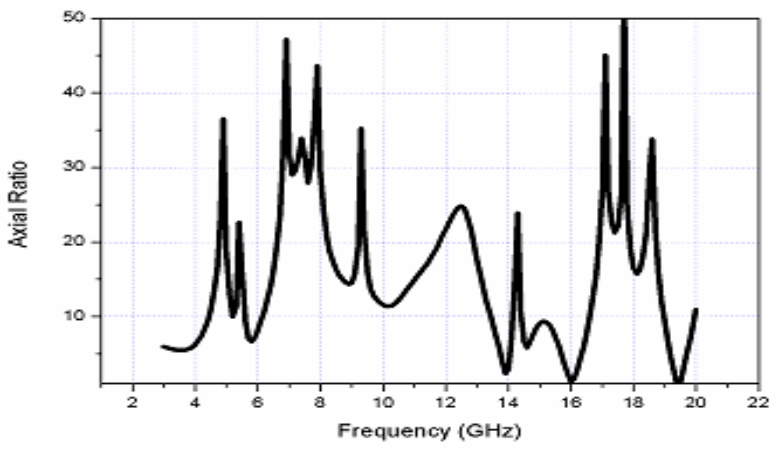

Fig. (9) Axial ratio of the antenna

\section{CONCLUSION}

Presented antenna is a compact and low profile solution of the space constraint of Ultra wide band technology of the wireless communication. This design provides high peak gain of $6.4 \mathrm{~dB}$ and a high bandwidth of $12.24 \mathrm{GHz}$ ranging from 4.2-16.6 GHz. Average radiation efficiency is above $90 \%$ and group delay provided is also $<1.2 \mathrm{~ns}$. At the same time noise interference is also avoided by creating a notch for Wi-Fi and ITU band. Antenna is simulated in both ANSOFT HFSS and CST MWS software. A high degree of coherence is achieved in the results obtained from both software.

\section{REFERENCES}

1. Luk, K.M. and K.W. Leung, 2003. Dielectric resonator antennas, Research Studies Press Baldock, England.

2. Petosa ,A. ,2007. Dielectric Resonator Antennas Handbook. Artech House, Norwood, USA.

3. Tayeb A. Denidni, Qinjiang Rao, Abdel R. Sebak "Broadband L-Shaped Dielectric Resonator Antenna”. IEEE ANTENNAS AND WIRELESS PROPAGATION LETTERS, VOL. 42005.

4. Yang Gao, Zhenghe Feng, and Li Zhang,"Compact Asymmetrical T-Shaped Dielectric Resonator Antenna for Broadband Applications" IEEE TRANSACTIONS ON ANTENNAS AND PROPAGATION, VOL. 60, NO. 3, MARCH 2012

5. Ahmed A. Kishk, Ricky Chair, Kai Fong Lee," Broadband Dielectric Resonator Antennas Excited by L-Shaped Probe" IEEE TRANSACTIONS ON ANTENNAS AND PROPAGATION, VOL. 54, NO. 8, AUGUST 2006.

6. Xian-Ling Liang, Tayeb A. Denidni, Li-Na Zhang," Wideband L-Shaped Dielectric Resonator Antenna With a Conformal Inverted-Trapezoidal Patch Feed" IEEE TRANSACTIONS ON ANTENNAS AND PROPAGATION, VOL. 57, NO. 1, JANUARY 2009.

7. Kenny Seungwoo Ryu, Ahmed A. Kishk," Ultrawideband Dielectric Resonator Antenna With Broadside Patterns Mounted on a Vertical Ground Plane Edge" IEEE TRANSACTIONS ON ANTENNAS AND PROPAGATION, VOL. 58, NO. 4, APRIL 2010.

8. Kenny Seungwoo Ryu, Ahmed A. Kishk," UWB Dielectric Resonator Antenna Having Consistent Omnidirectional Pattern and Low Cross-Polarization Characteristics" IEEE TRANSACTIONS ON ANTENNAS AND PROPAGATION, VOL. 59, NO. 4, APRIL 2011.

9. M. Abedian, S. K. A. Rahim, and M. Khalily, "Two-Segments Compact Dielectric Resonator Antenna for UWB Application" IEEE ANTENNAS AND WIRELESS PROPAGATION LETTERS, VOL. 11, 2012.

10. Raghvendra Kumar Chaudhary, Rajnish Kumar, Kumar Vaibhav Srivastava," Wideband Ring Dielectric Resonator Antenna with Annular-Shaped Microstrip Feed” 2013 IEEE.

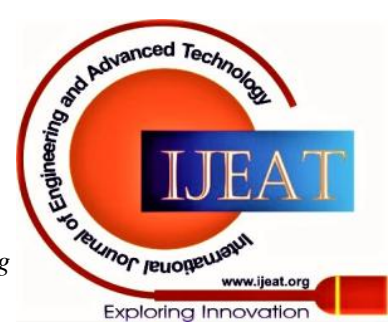


11. A. H. Majeed, A. S. Abdullah, F. Elmegri, K. H. Sayidmarie, R. A. Abd-Alhameed, and J. M. Noras," Aperture-Coupled Asymmetric Dielectric Resonators Antenna for Wideband Applications" IEEE ANTENNAS AND WIRELESS PROPAGATION LETTERS, VOL. 13, 2014.

12. C.-E. Zebiri, M. Lashab, D. Sayad, I.T.E. Elfergani, K.H.Sayidmarie, F. Benabdelaziz, R.A. Abd-Alhameed, J.Rodriguez, J.M. Noras," Offset Aperture-Coupled Double-Cylinder Dielectric Resonator Antenna with Extended Wideband" 2017 IEEE.

13. Poonam Kshirsagar, Shubha Gupta \& Biswajeet Mukherjee," A two-segment rectangular dielectric resonator antenna for ultra-wideband application" 2017 Taylor \& Francis.

14. Mohammad Abedian, Homayoon Oraizi, Sharul Kamal Abdul Rahim, Shadi Danesh, Muhammad Ridduan Ramli, Mohamad Haizal Jamaluddin, "Wideband rectangular dielectric resonator antenna for low-profile applications" . IET Microwave. Antennas Propagation., 2018, Vol. 12 Iss. 1, pp. 115-119.

15. Yangzhou Shao, Yuehe Ge*, Yinyan Chen, and Hai Zhang, "Compact Band-Notched UWB Dielectric Resonator Antennas" Progress In Electromagnetics Research Letters, Vol. 52, 87-92, 2015.

16. M. Abedian, S. K. A. Rahim, Sh. Danesh, S. Hakimi, L. Y. Cheong, and M. H. Jamaluddin, "Novel Design of Compact UWB Dielectric Resonator Antenna With Dual-Band-Rejection Characteristics for WiMAX/WLAN Bands" IEEE ANTENNAS AND WIRELESS PROPAGATION LETTERS, VOL. 14, 2015.

\section{AUTHORS PROFILE}

\begin{tabular}{|c|c|}
\hline & $\begin{array}{l}\text { Taruna Sharma is an agle and innovative } \mathrm{PhD} \text { scholar in Departm ent of } \\
\text { Electronics \& Comm unication at J. C. Bose University of Science and } \\
\text { Technology, YMCA, Faridabad, India. Her qualification comprises of } \\
\text { Diplom a, B.E. and M. Tech. in Electronics \& Comm munication. She has keen } \\
\text { interest in the field of RF Applications, Microwave \& RadarCommunication, } \\
\text { Optics, Graphene and related technologies. Her vision is to improve } \\
\text { microwave and millim eter antenna technologies to eradicate societal } \\
\text { problem s. }\end{array}$ \\
\hline & $\begin{array}{l}\text { Dr. Parikshit Va sisht Working as Controller of Ex am inations, and Assistant } \\
\text { Prof essor in Apeejay Stya University with a dem onstrated history of working } \\
\text { in the higher educationindustry of over } 17 \text { years. Skilled in Lecturing. Public. } \\
\text { Speaking.Science.and Research. Strong educationprof essional with a } \\
\text { B.Tech(ECE), has recently done his PhD from BIT, Mesra, Ranchi } \\
\text { (Jharkhand)in Antenna and Microwave communications. He has published } \\
\text { several research articles in reputed journals and International conf erences. }\end{array}$ \\
\hline & $\begin{array}{l}\text { Dr. Munish Vashishath hasteaching and research ex perience of } 22 \text { years. He } \\
\text { is presently working as Professor in Departm ent of Electronics and } \\
\text { Comm unication atJ. C. Bose University of Science and Technology, YMCA, } \\
\text { Faridabad, India. He acquired his PhD from Thapar University Patiala, India } \\
\text { in } 2009 \text { in the field of Sem iconductor Devices. His research interests are } \\
\text { sem iconductor devices, signal processing and antennas. He has published } \\
\text { m ore than } 80 \text { papers in various reputed journals. }\end{array}$ \\
\hline & $\begin{array}{l}\text { R. S. Yaduxanshi, has } 26 \text { years of teaching and research experience. He has } \\
\text { successfully implemented fighter aircraft arresting barrer projects at selected } \\
\text { flying stations of IndianAir Force. He has worked on Indigenization projects of } \\
\text { 3D radars at BEL and visited France for Radar Modemization as Senior } \\
\text { Scientific Officer in Min of Defense. He is working as professor at Ambedakar } \\
\text { Institute of AdvancedCommunication Technologies and Research (AIACTR), } \\
\text { Govt. of Delhi, India. }\end{array}$ \\
\hline
\end{tabular}

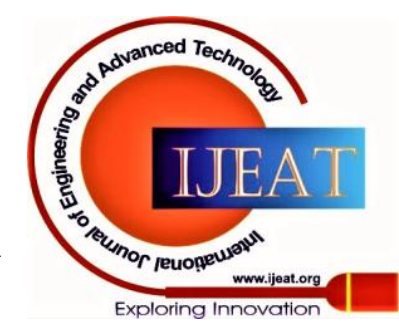

